\title{
https://doi.org/10.46813/2021-131-041 \\ MODELING OF ICRH SLOW WAVE PROPAGATION AND ABSORPTION IN WENDELSTEIN 7-X STELLARATOR
}

\author{
D. Grekov ${ }^{1,2}$, Yu. Turkin ${ }^{3}$ \\ ${ }^{1}$ Institute of Plasma Physics, National Science Center \\ “Kharkov Institute of Physics and Technology", Kharkiv, Ukraine; \\ ${ }^{2}$ V.N. Karazin Kharkiv National University, Kharkiv, Ukraine; \\ ${ }^{3}$ Max Planck Institute for Plasma Physics, Greifswald, Germany

\section{E-mail:grekov@ipp.kharkov.ua}

The propagation and absorption of slow waves in the plasma of the Wendelstein 7-X stellarator was investigated by the ray tracing. The aim of the work was to obtain a qualitative picture of the penetration into the plasma of a wave excited by the potential difference between the antenna conductors and the antenna box. For this, a ray code was used, which performs calculations in the magnetic configuration of the stellarator obtained by the VMEC code. A strong influence of the type of magnetic configuration ("higher mirror", "lower mirror", or standard configuration) on the propagation and absorption of a slow wave was found.

PACS: 52.27.Ny

\section{INTRODUCTION}

Installation of Ion Cyclotron Resonance Heating (ICRH) system is foreseen in the Wendelstein 7-X (W 7-X) stellarator in the near future. The main goal of the ICRH is to create sufficiently energetic ions in order to investigate their confinement in the optimized stellarator at fusion-relevant conditions. The main features of the W 7-X ICRH system are given in [1]. It should be noted that, when studying the interaction of the ICRH antenna with the $\mathrm{W} 7-\mathrm{X}$ plasma, the main attention was paid to the coupling and absorption of the fast wave. The electric field of this wave is polarized in the poloidal direction at the plasma edge. It is fast wave (FW) that is launched by the current-carrying conductors of the ICRH antenna. The other part of the radio frequency (RF) power is transmitted to the plasma due to toroidal $\mathrm{RF}$ electric field. This electric field is due to the oscillating differences of the potentials in the gap between the unshielded current-caring conductors and in the gaps between the conductors and the grounded antenna box. The essential part of this RF power is radiated as the slow wave (SW), which has the electric field component in the toroidal direction.

Therefore it is very important to find out location of the SW penetration and absorption regions. It is impossible to carry out this problem analytically due to complicate 3D structure of the torsatron magnetic surfaces and confining field. Moreover, the numerical modeling of full wave problem faces insuperable difficulties caused by $3 \mathrm{D}$ inhomogeneity and problem stiffness. On the other hand, for typical plasma periphery parameters (electron density $n_{e} \sim 10^{12} \mathrm{~cm}^{-3}$ and electron temperature $T_{e} \sim 25 \mathrm{eV}$ [2]) the $\mathrm{SW}$ wavelength is much less than the average plasma radius. Therefore geometrical optics approximation is valid for this analysis.

\section{BASIC EQUATIONS}

Propagation of SW in the W 7-X plasma was studied using the ray tracing code. The VMEC equilibrium data were used in the calculations. A "standard" magnetic configuration [3] was used in most calculations (Fig. 1).

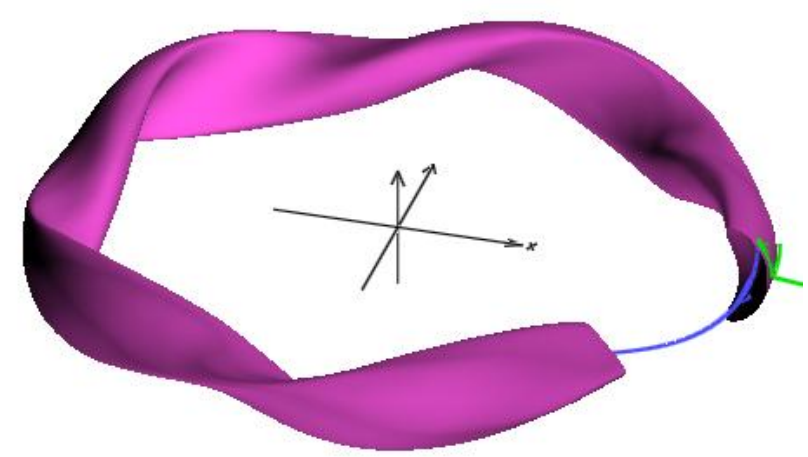

Fig. 1. Last closed magnetic surface of W 7-X (standard configuration) obtained by VMEC code

A "lower-mirror" configuration and a "higher-mirror" configuration were used for comparison. The code solves the equations

$$
\frac{d \vec{r}}{d t}=\frac{\partial D_{R}}{\partial \vec{k}} / \frac{\partial D_{R}}{\partial \omega}, \quad \frac{d \vec{k}}{d t}=-\frac{\partial D_{R}}{\partial \vec{r}} / \frac{\partial D_{R}}{\partial \omega},
$$

where $\vec{k}$ is the wave vector, $\omega$ is the wave frequency, $t$ is time, $\vec{r}$ is the ray spatial coordinates and $D(\omega, \vec{r}, \vec{k})=0$ is the $\mathrm{SW}$ dispersion equation in the form

$$
D=D_{R}+i D_{I}=\varepsilon_{1} N_{\perp}^{2}+\varepsilon_{3}\left(N_{\|}^{2}-\varepsilon_{1}\right)=0 .
$$


Here $N_{\perp}=c k_{\perp} / \omega, N_{\|}=c k_{\|} / \omega, k_{\perp}=\left(k^{2}-k_{\|}^{2}\right)^{1 / 2}$ and

$$
k_{\|}=\vec{k} \cdot \vec{B} / B=\left(b_{R} k_{R}+b_{\varphi} k_{\varphi}+b_{Z} k_{Z}\right)
$$

Cylindrical coordinates with axis along the stellarator axis are used. Components of plasma dielectric permeability tensor $\varepsilon_{1}$ and $\varepsilon_{3}$ are defined as

$$
\begin{aligned}
& \varepsilon_{1}=1-\sum_{\alpha} \frac{\omega_{p \alpha}^{2}}{\omega^{2}-\omega_{c \alpha}^{2}}+ \\
& +\sum_{\alpha} i \sqrt{\frac{\pi}{8}} \frac{\omega_{p \alpha}^{2}}{\left|k_{\|}\right| v_{T \alpha} \omega} \exp \left[-\frac{\left(\omega-\omega_{c \alpha}\right)^{2}}{2 k_{\|}^{2} v_{T \alpha}^{2}}\right], \\
& \varepsilon_{3}=1+\frac{\omega_{p e}^{2}}{k_{\|}^{2} v_{T e}^{2}}\left[1+i \sqrt{\pi} z_{e} W\left(z_{e}\right)\right]+i \varepsilon_{3 c o l l},
\end{aligned}
$$

where $\omega_{p \alpha}^{2}=4 \pi e^{2} n_{\alpha} / m_{\alpha}$ is plasma frequency of $\alpha$ ions, $\alpha=H, D, H e^{3}, \omega_{c \alpha}=e B / c_{\alpha}$ is $\alpha$ ions cyclotron frequency, $\quad v_{T \alpha}=\sqrt{T_{\alpha} / m_{\alpha}}$ is $\alpha$ ions thermal velocity, $\omega_{p e}^{2}=4 \pi e^{2} n_{e} / m_{e}$ is plasma frequency of electrons, $v_{T e}=\sqrt{T_{e} / m_{e}}$ is thermal velocity of electrons, $z_{e}=\omega / \sqrt{2}\left|k_{\|}\right| v_{T e}, W\left(z_{e}\right)$ is plasma dispersion function, $\varepsilon_{3 c o l l}=\omega_{p e}^{2} \nu_{e f f} / \omega^{3}$ and $v_{e f f}$ is effective collisional frequency of electrons $v_{e f f}=\frac{4}{3} \sqrt{\frac{2 \pi}{m_{e}}} \frac{e^{4} Z^{2} \Lambda n_{e}}{T_{e}^{3 / 2}}, \Lambda$ is the Coulomb logarithm.

Power associated with certain ray $Q$ is defined as $Q=Q_{0} e^{-\Gamma}$, where $Q_{0}$ is the initial RF power at the ray starting point and $\Gamma=\int_{0}^{t} \gamma d t$,

$$
\gamma=-\frac{D_{I}}{\partial D_{R} / \partial \omega}, D_{I}=\operatorname{Im} \varepsilon_{1}\left(N_{\perp}^{2}-\varepsilon_{3}\right)+\operatorname{Im} \varepsilon_{3}\left(N_{\|}^{2}-\varepsilon_{1}\right) .
$$

When calculating $Q$ along the ray, electron Landau damping, ion cyclotron damping and collisional damping were taken into account.

The plasma density (and temperature) profiles were set as

$$
n(\psi)=\left\{\begin{array}{c}
n_{0} \frac{\exp (\xi)-\exp (A \xi \psi)}{\exp (\xi)-1}, \quad \psi \leq 1 \\
n_{b}+\left(n_{x}-n_{b}\right) \exp [(1-\psi) / \delta], \quad \psi>1,
\end{array}\right.
$$

where $\psi$ is the flux surface label $(\psi=0$ at the plasma center, $\psi=1$ at the last closed magnetic surface (LCMS)), $A$ is stapling coefficient, $n_{x}$ is density at the LCMS, $\xi$ is parameter ( $\xi=4$ for density and $\xi=-2$ for temperature) and $\delta$ is the e-folding length outside the LCMS. The following set of parameters has been used: $\mathrm{B}_{0}=25.9 \mathrm{kGs}, \mathrm{n}_{\mathrm{e} 0}=7 \cdot 10^{13} \mathrm{~cm}^{-3}, \mathrm{n}_{\mathrm{eb}}=5 \cdot 10^{11} \mathrm{~cm}^{-3}$, $\mathrm{n}_{\mathrm{H}} / \mathrm{n}_{\mathrm{e}}=0.6, \mathrm{n}_{\mathrm{D}} / \mathrm{n}_{\mathrm{e}}=0.3, \mathrm{n}_{\mathrm{He} 3} / \mathrm{n}_{\mathrm{e}}=0.01, \mathrm{~T}_{\mathrm{e} 0}=1 \mathrm{keV}$, $\mathrm{T}_{\mathrm{eb}}=5 \mathrm{eV}, \mathrm{f}=\omega / 2 \pi=25 \mathrm{MHz}$ for most part of calculations.

\section{ICRH ANTENNA AND SW SPECTRUM}

Simplified layout of the W 7-X unshielded antenna $[1,4]$ is shown in Fig. 2.

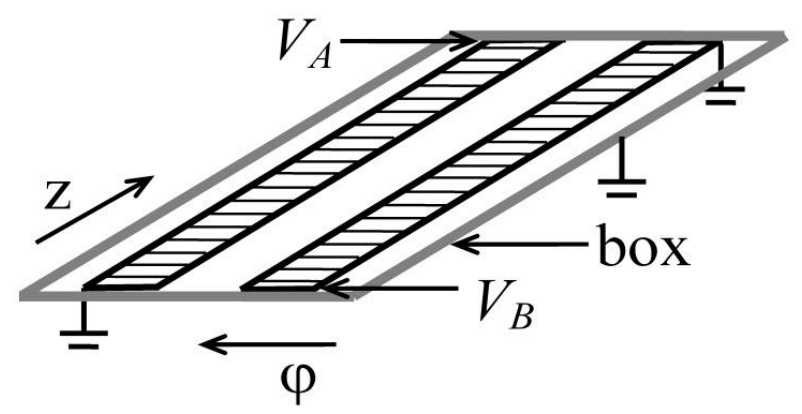

Fig. 2. Layout of the W 7-X ICRH antenna

Two poloidal antenna straps and grounded antenna box are seen in Fig. 2. The gaps $b$ between antenna straps and box, numbered as 1 (left) and 3 (right), are $3 \mathrm{~cm}$ each. The gap $a$ between straps, numbered as 2 , is $10 \mathrm{~cm}$. Width of each strap is $9 \mathrm{~cm}$ and length $L$ is $82 \mathrm{~cm}$. Only (0 0$)$ relative phasing of antenna straps is considered in this paper. With this relative phasing, the input voltage $V_{A}=-V_{B}=V$. The voltage $V_{A}\left(V_{B}\right)$ decreases (increases) to the grounded end of the strap linearly. Such voltage distribution causes electric field $E_{\varphi}$ in the gaps (see Fig. 3).

$$
\begin{aligned}
& E_{\phi 1}=-\frac{V}{b}\left(\frac{z}{L}+\frac{1}{2}\right), \\
& E_{\phi 2}=-\frac{V}{a}, \quad-\frac{L}{2} \leq z \leq \frac{L}{2}, \\
& E_{\phi 3}=\frac{V}{b}\left(\frac{z}{L}-\frac{1}{2}\right) .
\end{aligned}
$$

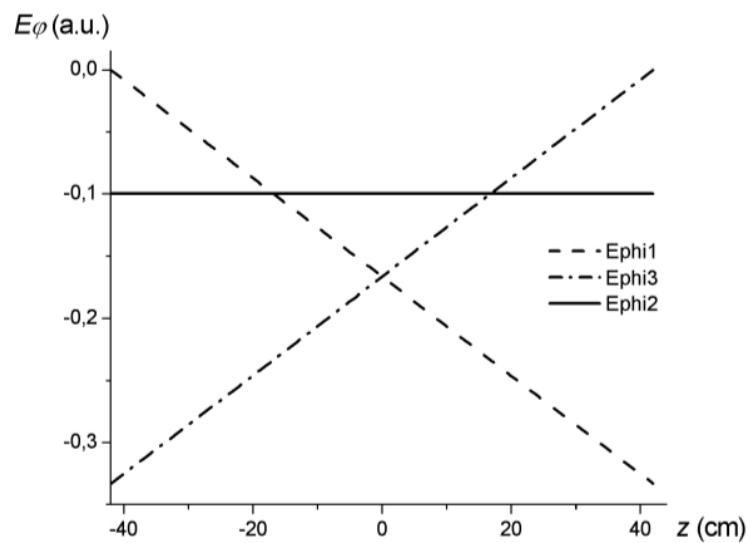

Fig. 3. Toroidal electric field distributions in poloidal direction $(V=1)$

$E_{\varphi}$ distributions were expanded into Fourier series of poloidal $(m)$ and toroidal $(l)$ angles (Figs. 4, 5). 


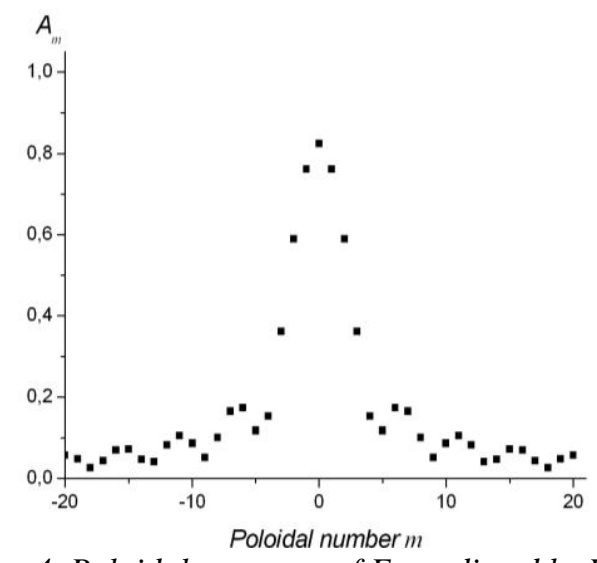

Fig. 4. Poloidal spectrum of $E_{\varphi}$ radiated by $W 7-X$ ICRH antenna at $(00)$ relative phasing of the straps

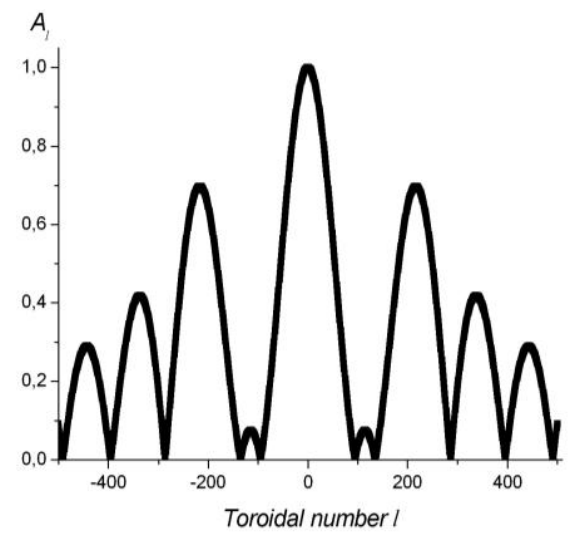

Fig. 5. Toroidal spectrum of $E_{\varphi}$, radiated by $W 7-X$ ICRH antenna at $(00)$ relative phasing of the straps

Most of the RF power is in poloidal harmonics with $|\mathrm{m}| \leq 4$. At the same time, the toroidal spectrum is rather wide (see Fig. 5).

As is known, when the condition

$$
0.2 \leq z_{e} \leq 2
$$

is satisfied, SW are strongly absorbed by plasma electrons due to Landau damping. By analogy with investigations of FW heating in tokamaks, one could define $k_{\|}$ as $k_{\|}=(l+m z) / R[1,4]$ ( $R$ is the big radius of the torus, $\boldsymbol{t}$ is the rotational transform angle, $\boldsymbol{t} \approx 0.9$ at the plasma edge) and conclude from (9) that the harmonics with $l>l_{L D}$ are strongly damped. Here $l_{L D} \approx \omega \mathrm{R} / 3 v_{\mathrm{Te}}$. Assuming that near the antenna $\mathrm{T}_{\mathrm{e}} \approx 25 \mathrm{eV}$ and $\mathrm{R}=620 \mathrm{~cm}$, it turns out $l_{\mathrm{LD}}=150$. But, as ray tracing calculations show, this approach is inapplicable for a slow wave. In expression (3), along with $\mathrm{k}_{\varphi} \mathrm{b}_{\varphi}$, an important role is played by the term $k_{R} b_{R}$. Therefore, the propagation of harmonics with $l \geq l_{L D}$ is possible. Below, each combination of poloidal $m$ and toroidal $l$ harmonics was traced independently.

\section{RAY TRACING CALCULATIONS}

The W 7-X ICRH antenna is located at $\varphi=7.4^{\circ}$ from minor cross-section, where magnetic surfaces are beenshaped. It is antenna port AEE 3.1. Antenna angular length in toroidal direction is $\Delta \varphi=3^{\circ}$ or $0.52 \mathrm{rad}$. To start calculation of any specific ray, the initial values $\vec{r}_{0}=\left(R_{0}, \varphi_{0}, z_{0}\right)$ and $\vec{k}_{0}=\left(k_{R 0}, l_{0}, k_{z 0}\right)$ must be determined. The representative values $l_{0}= \pm 50, \pm 215, \pm 340$ were used. The value of $k_{z 0}$ was defined as $k_{z 0}=\frac{m_{0}}{\bar{a}} \cos \left[\operatorname{arctg}\left(z_{0} / R_{0}\right)\right]$, where $m_{0}=3,\left|z_{0}\right| \leq 40 \mathrm{~cm}$ and $\bar{a}=55 \mathrm{~cm}$ is a mean minor radius. This value has a little effect on calculation results. The value of $R_{0}$ was determined from the condition $\psi_{0}=1.134$. With this value of $\psi_{0}$, plasma density $n_{e} \approx 5 \cdot 10^{12} \mathrm{~cm}^{-3}$ at the starting points.

Further, the initial value of $k_{R}$ was determined from the dispersion equation in the form

$k_{R 0}^{2}\left[\varepsilon_{1}\left(1-b_{R}^{2}\right)+\varepsilon_{3} b_{R}^{2}\right]+2 k_{R 0} b_{R}\left(k_{\phi 0} b_{\phi}+k_{z 0} b_{z}\right)\left(\varepsilon_{3}-\varepsilon_{1}\right)+$

$+\varepsilon_{1}\left[k_{\phi 0}^{2}+k_{z 0}^{2}-\left(k_{\phi 0} b_{\phi}+k_{z 0} b_{z}\right)^{2}\right]+\varepsilon_{3}\left(k_{\phi 0} b_{\phi}+k_{z 0} b_{z}\right)^{2}-$

$-\frac{\omega^{2}}{c^{2}} \varepsilon_{1} \varepsilon_{3}=0$.

More informative for understanding the further propagation of the SW are the components $k_{\perp 0}$ and $k_{\mid 0}$. It is worth to note that the sign of $k_{\perp 0}$ is determined by the sign of $l_{0}$ and the sign of $k_{\| 0}$ depends only on the root number. Moreover, $\left|k_{||}\right|$practically does not depend on $l_{0}$ sign and root number.

In order to consider SW propagation, the antenna surface was divided into fifteen parts. There were three rows with coordinates $\varphi_{0}=0.103,0.129,0.155$ in the toroidal direction and five rows with coordinates $\mathrm{z}_{0}=0$, $\pm 20 ; \pm 40 \mathrm{~cm}$ in the poloidal direction. Six rays with different $l_{0}$ were traced at each point.

Typical dependencies of ray parameters are shown in Figs. 6-8. The ray displacement from initial magnetic surface (see Fig. 8) is quite small $\nabla \psi \approx 0.045$, what in terms of mean minor radius is $\Delta \bar{a} \approx 2.5 \mathrm{~cm}$.

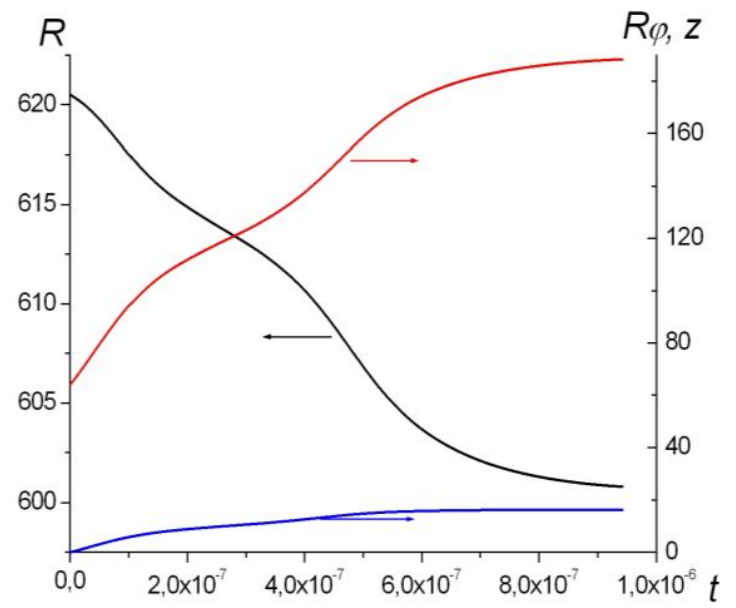

Fig. 6. Ray coordinates vs time along the ray for $\varphi_{0}=0.103, z_{0}=0.0 \mathrm{~cm}, l_{0}=-50$ 


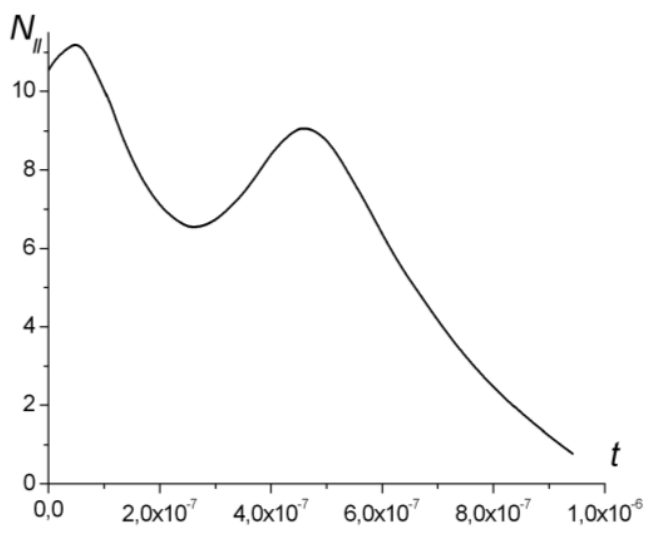

Fig. 7. Variation of $N_{\|} v$ s time along the ray for $\varphi_{0}=0.103, z_{0}=0.0 \mathrm{~cm}, l_{0}=-50$

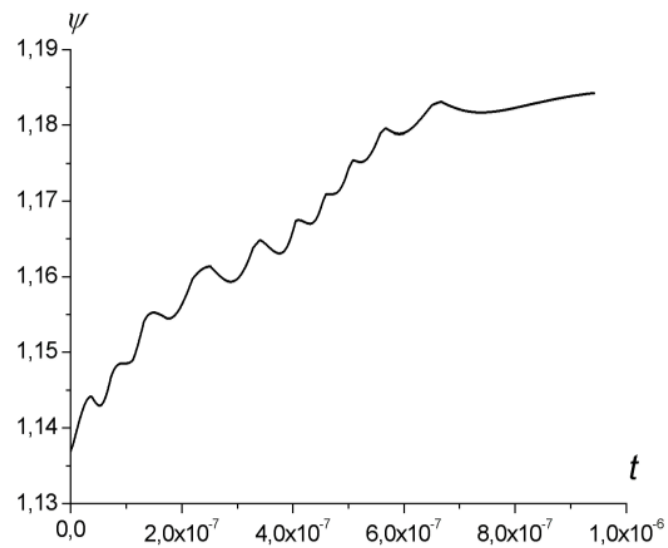

Fig. 8. Variation of $\psi$ vs time along the ray for $\varphi_{0}=0.103, z_{0}=0.0 \mathrm{~cm}, l_{0}=-50$

This is very small compared to the displacement in the toroidal direction $\Delta(\mathrm{R} \varphi) \approx 110 \mathrm{~cm}$ (see Fig. 6). The change in $R$ (see Fig. 6) is mainly due to the change in the shape of the magnetic surfaces when the ray moves along the torus. The variation of $N_{\|}$along the ray (see Fig. 7) is inherent in a slow wave. A similar change occurs in the low hybrid frequency band [5]. It is determined by the change in the magnitude of the magnetic field along the ray.

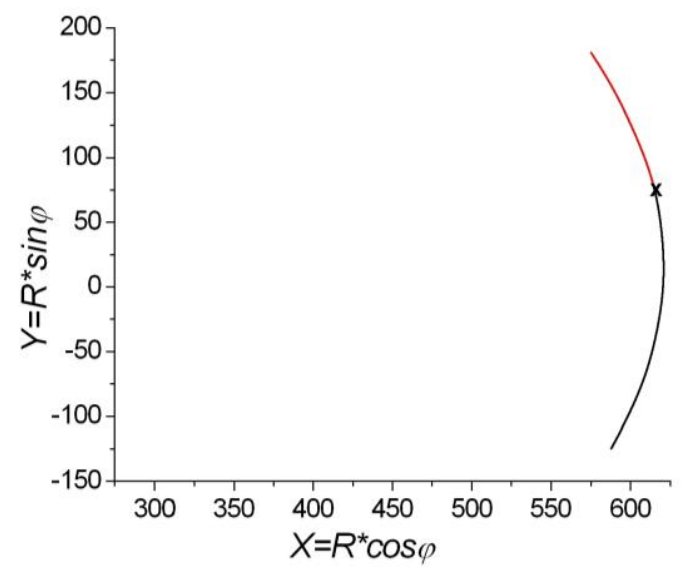

Fig. 9. Equatorial projection of rays with $l_{0}=215$ (red) and $l_{0}=-215$ (black). The starting point is marked with a $\operatorname{cross}\left(\varphi_{0}=0.129, z_{0}=0.0 \mathrm{~cm}\right)$
As it is shown in Fig. 9, rays with different sign of $l_{0}$ propagate in different toroidal directions. Moreover, red ray shifts to the lower density plasma and black ray shifts in the opposite direction. The larger the absolute value of the initial toroidal number, the further the SW moves away from the antenna in the toroidal direction and directions of $\pm \nabla \psi$.

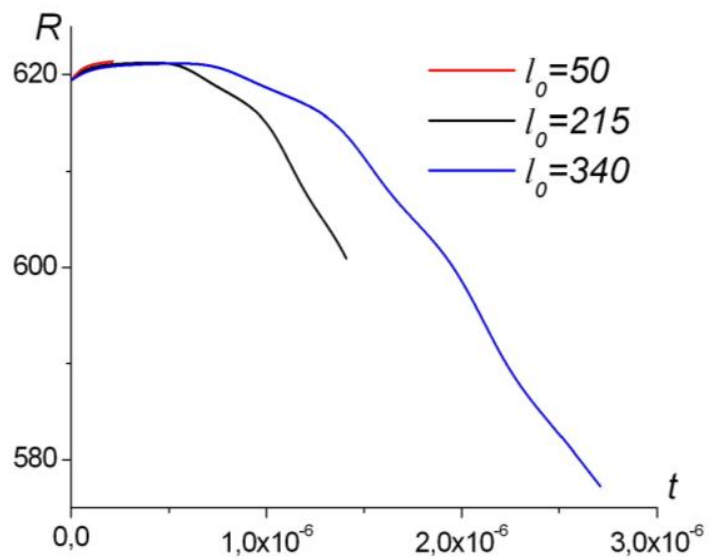

Fig. 10. Dependencies of $R$ on time along the ray for different values of $l_{0}\left(\varphi_{0}=0.129, z_{0}=0.0 \mathrm{~cm}\right)$

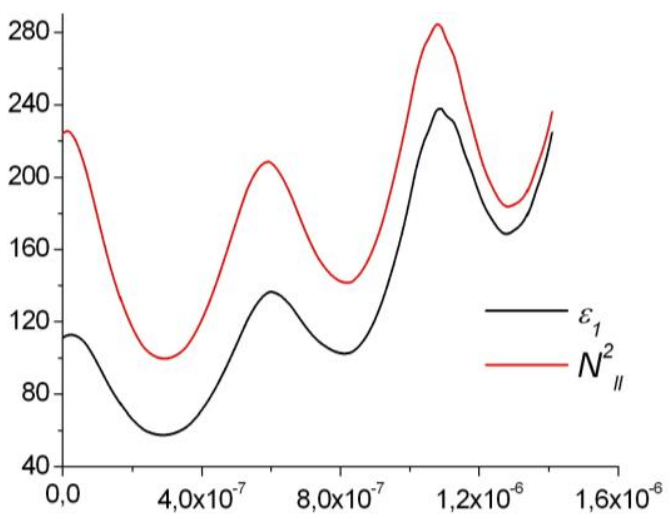

Fig. 11. Variation of $N_{\|}$and $\varepsilon_{1}$ vs time along the ray for $\varphi_{0}=0.129, z_{0}=0.0 \mathrm{~cm}, l_{0}=215$

The calculations performed showed that SW do not penetrate into the bulk plasma. Collisional absorption and Landau damping of this waves in the peripheral plasma is negligibly small. Rays were terminated in the vicinity of $\varepsilon_{1}-N_{\|}^{2} \approx 0$ regions, where SW converts into FW (see Fig. 11).

\section{MAGNETIC CONFIGURATION EFFECTS}

In order to find out whether the magnetic configuration of the stellarator affects the propagation of a SW, calculations were carried out in the configurations "lower mirror" (LM) and "higher mirror" (HM) [3]. It was found that with a change in the magnetic configuration, not only the propagation, but also the absorption of the SW changes greatly (Fig. 12).

For cases HM, $l_{0}=-340$ and LM, $l_{0}=340$, the waves do not penetrate the plasma at all. In addition, for some rays, strong Landau damping was found (Fig. 13). In this case, the calculation was stopped because of $\operatorname{Im} \varepsilon_{3} \sim \operatorname{Re} \varepsilon_{3}$ or $\operatorname{Im} D \sim \operatorname{Re} D$. 


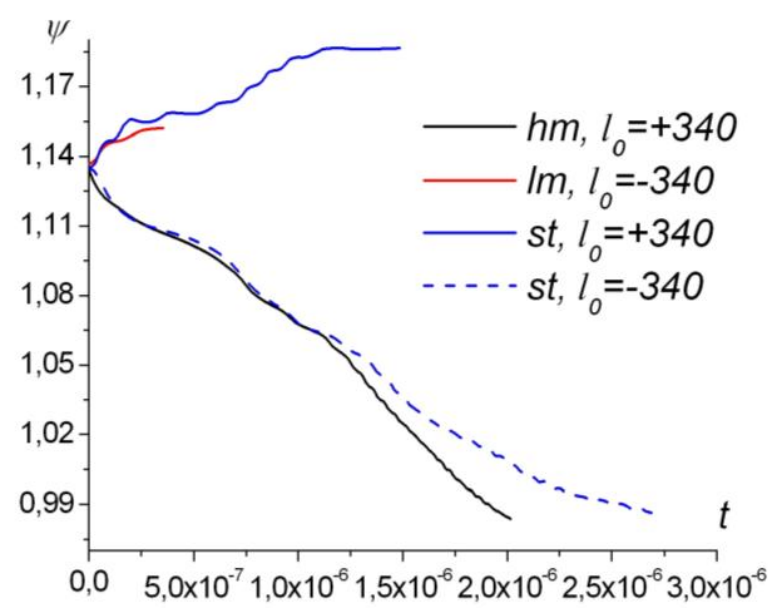

Fig. 12. Variation of $\psi$ vs time along the ray for different magnetic configurations

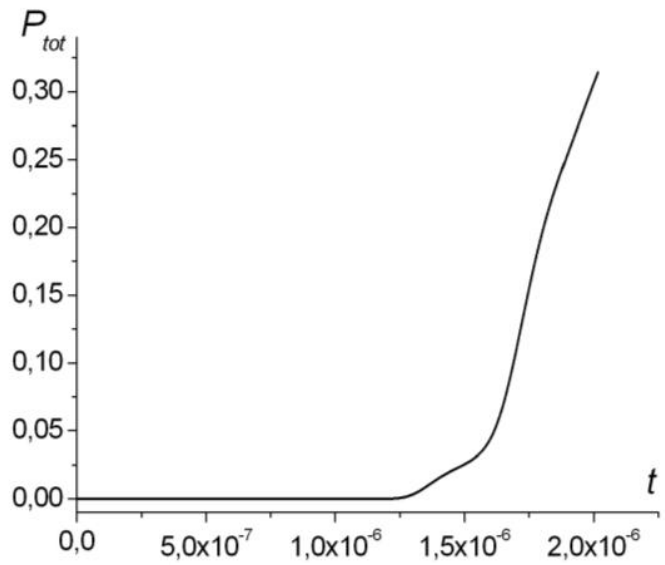

Fig. 13. Absorbed power vs time along the ray for $l_{0}=340$, HM configuration

\section{CONCLUSIONS}

The features of SW propagation and absorption in the W 7-X plasma were investigated. It was revealed that these waves penetrate poorly the plasma core and propagate along the plasma periphery above all. Some part of the radiated as a SW RF power is absorbed by electrons due to Landau damping. Some part is absorbed through the resonance $\varepsilon_{1}=0$. But the most part is converted to FW near the antenna region.

\section{AKNOWLEDGEMENTS}

This work was partially supported by the Ministry of Science and Education of Ukraine under the contract N 22-13-20. This work has been carried out within the framework of the EUROfusion Consortium and has received funding from the Euratom research and training programme 2014-2018 and 2019-2020 under Grant Agreement No. 633053. The views and opinions expressed herein do not necessarily reflect those of the European Commission.

\section{REFERENCES}

1. J. Ongena et al. // Phys. of Plasmas. 2014, v. 21, p. 061514.

2. T.S. Pedersen et al. // Phys. of Plasmas. 2017, v. 24, p. 055503 .

3. A. Dinklage et al. // Nature Phys. 2018, v. 14, p. 855860.

4. J. Ongena et al. / Proc. 19th Top. Conf. Rf Power In Plasmas, AIP Conf. Proc. 2011, v. 1406, p. 265.

5. D. Grekov et al. // Nuclear Fusion. 1990, v. 30, p. 2039.

Article received 22.01.2021

\title{
МОДЕЛИРОВАНИЕ РАСПРОСТРАНЕНИЯ И ПОГЛОЩЕНИЯ МЕДЛЕННОЙ ВОЛНЫ ПРИ ИОННОМ ЦИКЛОТРОННОМ НАГРЕВЕ В СТЕЛЛАРАТОРЕ ВЕНДЕЛЬШТЕЙН 7-Х
}

\author{
Д. Греков, Ю. Туркин
}

Распространение и поглощение медленной волны в плазме стелларатора Вендельштейн 7-Х было исследовано методом лучевых траекторий. Цель работы - получение качественной картины проникновения в плазму волны, возбуждаемой за счет разности потенциалов между проводниками антенны и антенным боксом. Для этого использован лучевой код, который выполнял расчеты в магнитной конфигурации стелларатора, полученной кодом VMEC. Обнаружено сильное влияние вида магнитной конфигурации (усиленные гофры, уменьшенные гофры или стандартная конфигурация) на распространение и поглощение медленной волны.

\section{МОДЕЛЮВАННЯ ПОШИРЕННЯ ТА ПОГЛИНАННЯ ПОВІЛЬНОЇ ХВИЛІ ПРИ ІОННОМУ ЦИКЛОТРОННОМУ НАГРІВАННІ В СТЕЛАРАТОРІ ВЕНДЕЛЬШТЕЙН 7-Х}

\section{Д. Греков, Ю. Туркін}

Поширення і поглинання повільної хвилі в плазмі стеларатора Вендельштейн 7-Х було досліджено методом променевих траєкторій. Мета роботи - отримання якісної картини проникнення в плазму хвилі, що збуджується за рахунок різниці потенціалів між провідниками антени і антенним боксом. Для цього використаний променевий код, який виконував розрахунки в магнітній конфігурації стеларатора, що отримана кодом VMEC. Виявлено сильний вплив виду магнітної конфігурації (посилені гофри, зменшені гофри або стандартна конфігурація) на поширення і поглинання повільної хвилі. 